\title{
Validation of Petroleum Hydrocarbons Determination in Soil by Fourier Transform Infrared Spectroscopy
}

\author{
Erika LEVEI, Marin SENILA Oana CADAR, Marius ROMAN, Claudiu TANASELIA \\ INCDO-INOE 2000, Research Institute for Analytical Instrumentation, 67 Donath Street, 400293 Cluj- \\ Napoca, Romania; \\ * corresponding author: erika.levei@icia.ro
}

Bulletin USAMV series Agriculture 71(2)/2014

Print ISSN 1843-5246; Electronic ISSN 1843-5386

DOI 10.15835/buasvmcn-agr: 10432

\begin{abstract}
The paper presents the validation and the estimation of the measurement uncertainty for the determination of petroleum hydrocarbons in soil by Fourier transform-infrared spectroscopy. For the method validation selectivity, limit of detection and limit of quantification, working range, trueness, precision and recovery were studied and the measurement uncertainty was evaluated based on the bottom-up approach. The method limit of quantification was found to be $30 \mathrm{mg} / \mathrm{kg}$, the working range $30-2500 \mathrm{mg} / \mathrm{kg}$, the recovery $105 \%$, while the measurement uncertainty was found to be $11 \%$.
\end{abstract}

Keywords: FT-IR spectroscopy, method validation, petroleum hydrocarbons, soil

\section{INTRODUCTION}

The large scale use of crude-oilas energy source and raw material in the petrochemical industry, has led to the increase of the environmental contamination with petroleum hydrocarbons by accidental or illegal spills, leakages or mismanagement of wastes and by-products (Schwartz et al., 2012). Soil contamination with petroleum hydrocarbons is one of the most challenging environmental problems as it negatively impacts the biological, chemical and physical properties of soil (Miclean et al., 2010; Okparanma, 2013). In order to develop efficient remediation strategies or to monitor the progress of the decontamination processes, precise data on petroleum products content in soil is required.

Usually, the petroleum products in soil are determined as total petroleum hydrocarbons (TPH). There are a wide variety of TPH determination methods (Okparanma, 2013; Paiga et al., 2012), however, the most used consist in the extraction of TPH from soil using different solvents and its quantification by gravimetry, infrared spectroscopy or gas-chromatography, in function of the expected concentration range and the required method performance parameters
(Paiga et al., 2012). Regardless of the used method, in order to provide reliable data on the TPH content the validation of the analytical procedure is a mandatory step. The TPH determination by FT-IR spectroscopy consist in the extraction of the petroleum hydrocarbons in a solvent with no $\mathrm{C}-\mathrm{H}$ bonds, the extract purification in order to eliminate the polar components, the recording of the extract's absorbance and comparison against a calibration curve. In the FT-IR spectra absorption peaks specific to the $\mathrm{C}-\mathrm{H}$ bonds stretching vibrations occurs within the wavenumber range of $3150-2750 \mathrm{~cm}^{-1}$ : saturated $\mathrm{CH}_{2}\left(\sim 2925 \mathrm{~cm}^{-}\right.$ $\left.{ }^{1}\right)$, terminal $\mathrm{CH}_{3}\left(\sim 2958 \mathrm{~cm}^{-1}\right)$ and aromatic C-H groups $\left(\sim 3030 \mathrm{~cm}^{-1}\right)$.

The method validation and the measurement uncertainty estimation are important steps of the method development process assuring that the produced analytical data are reliable (Drolc and Pintar, 2012).

The objectives of the paper are the validation and the estimation of the measurementuncertainty in order to determine the petroleum hydrocarbons in soil by Fourier Transform Infrared (FT-IR) spectroscopy. 


\section{MATERIALS AND METHODS} Experimental procedure

All reagents were of p.a. quality, purchased from Merck. Sandy Loam soil (CRM358, SigmaAldrich, USA) and 1/1 diesel oil/ lubricating oil mixture (BAMK010e, Federal Institute for Materials Research and Testing, Germany) certified reference materials (CRMs) were used for the validation procedure. The volumes were measured using calibrated glassware (Hirschmann, Germany).

The method consists in the extraction of $10 \mathrm{~g}$ of chemically dried (anhydrous sodium sulphate) soil with $50 \mathrm{ml}$ of perchloroethylene, removal of polar substances by filtration using Florisil columns and recording of the FT-IR spectra in the $3150-2750 \mathrm{~cm}^{-1}$ region. Standard solutions $(0.004,0.01,0.02,0.05,0.1,0.2,0.4$ and $0.5 \mathrm{mg} /$ $\mathrm{ml}$ prepared from a mixture of $1 / 1$ diesel oil/ lubricating oil CRM (BAM-K010e) were used for the calibration of the instrument. Measurements were carried out using a Spectrum BX II (Perkin Elmer, USA) spectrometer with DTGS detector. The measured absorbance was converted to TPH value using the linear regression model. The TPH content of soil is calculated according to equation
1, where: $C$-is the concentration of TPH in soil, $c$-is the concentration of TPH in the extract, $D f$-is the dilution factor, $C f$ - is the concentration factor, $V$ is the volume of the extract and $w$ is the weight of the sample.

$$
C\left[\frac{m g}{k g}\right]=\frac{c\left[\frac{m g}{m l}\right] \times D f \times V[m l]}{c f \times w[k g]} \quad \text { Eq. } 1
$$

The method steps are presented in fig. 1 .

For the method validation limit of detection (LoD) and limit of quantification (LoQ), working range, trueness and precision (repeatability and reproducibility) were studied. The LoD is the lowest concentration at which the analyte can be detected, while LoQ is the lowest concentration of the analyte that can be determined with an acceptable level of precision. In our case the LoD was calculated as the signal plus three times the standard deviation (s) of 10 independent measurements of a spiked blank solution $(0.001$ $\mathrm{mg} / \mathrm{l})$. The LoQ was calculated as 3 times the LoD. The working range represents the range of the analyte concentration over which the method can be applied. At the lower end the limiting factor

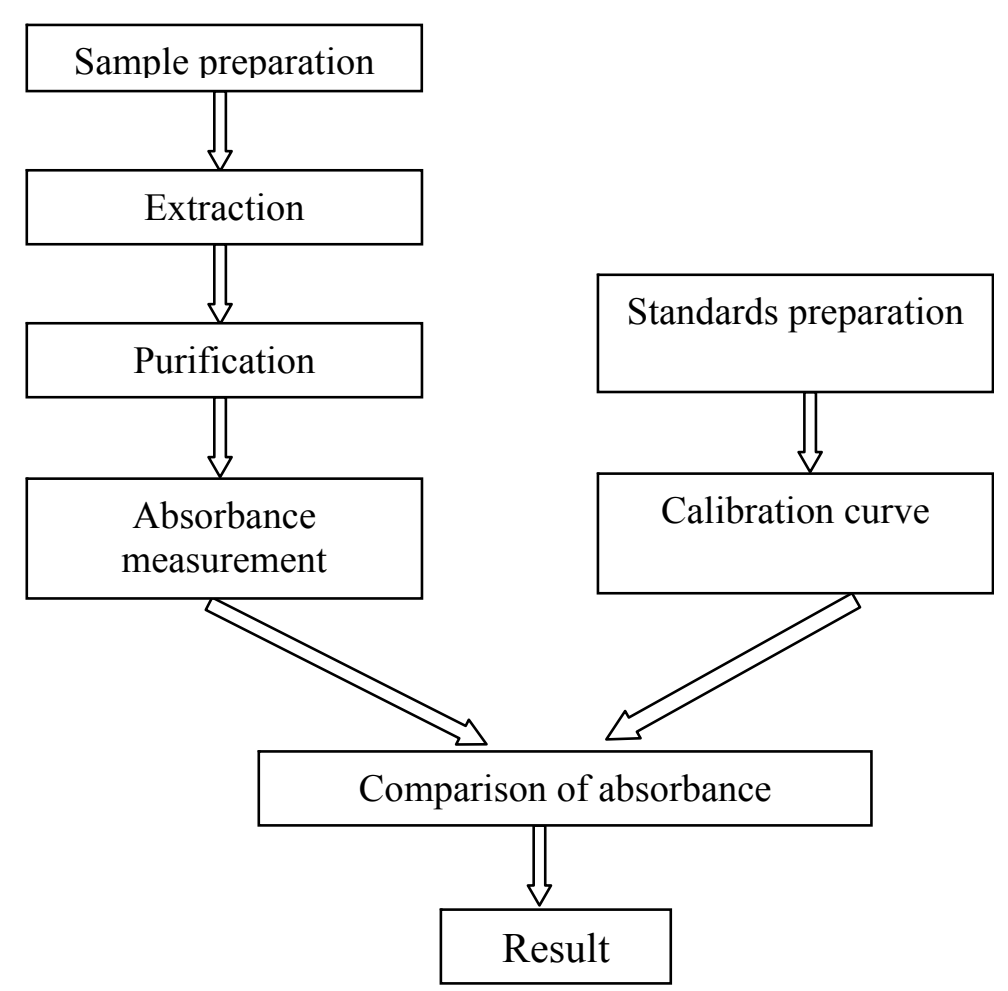

Fig. 1. Experimental procedure for the measurement of TPH is soil by FT-IR spectroscopy 
is the LoQ while at the upper end the limitation is imposed by the instrument response system. For the selected working range, the homogeneity of the variances of the lower and the higher concentration of the calibration curve was tested, for a significance level of 0.01 . The tested range factor was calculated as $\mathrm{PG}=\left(\mathrm{s}_{\text {low }}\right)^{2} /\left(\mathrm{s}_{\text {high }}\right)^{2}$ in case of $\mathrm{s}_{\text {low }}>\mathrm{s}_{\text {high }}$ and as $\mathrm{PG}=\left(\mathrm{s}_{\text {high }}\right)^{2} /\left(\mathrm{s}_{\text {low }}\right)^{2}$ in case of $\mathrm{s}_{\text {low }}<\mathrm{S}_{\text {high }}$. The obtained value was compared with the tabulated values for F-distribution. Trueness was estimated by CRM analysis (6 parallel CRM358 samples). To estimate the methods precision the repeatability and reproducibility of the determination were estimated, considering within and between days variation.

The measurement uncertainty was evaluated based on the bottom-up approach (ISO, 1995). The individual contributions were obtained from calibration certificates (Type A) and from statistical analysis of repeated measurements (Type B). The uncertainty of volumetric operations (volumetric flasks, pipettes) was calculated by using manufacturer data on calibration uncertainty (from certificates), the uncertainty associated with the use of glassware at a temperature different from that of calibration, and the repeatability of volumetric deliveries. Before calculating the combined uncertainty, type B uncertainties were expressed as standard deviation. If there were no data on the type of distribution, it was estimated as rectangular or triangular and then converted to a normal distribution by dividing the factors of $\sqrt{3} \sqrt{3}$ and $\sqrt{6} \sqrt{6}$, respectively (Ellison and Williams, 2012). All sources of uncertainty were combined according to the law of propagation of uncertainties, obtaining the combined standard uncertainty $(\mathrm{u})$. The final result was reported as expanded uncertainty $(\mathrm{U})$, calculated as $\mathrm{U}=\mathrm{k} \times \mathrm{u}$, where $\mathrm{k}$ is the coverage factor, corresponding to $\mathrm{a}$ $95 \%$ confidence level $(\mathrm{k}=2)$.

\section{RESULTS AND DISCUSSION Method validation}

The obtained LoD was $10 \mathrm{mg} / \mathrm{kg}$, while the LoQ was $30 \mathrm{mg} / \mathrm{kg}$. In order to confirm the calculated LoQ six replicates of a soil sample spiked with $1 / 1$ diesel oil/ lubricating oil mixture $(30 \mathrm{mg} /$ $\mathrm{kg}$ TPH) and subjected to analysis. The targeted repeatability expressed as relative standard deviation (RSD) was 20\%, while the targeted recovery was between $80 \%$ and $120 \%$. The experimental measurements (tab.1) confirmed that the repeatability and recovery at the LoQ are below the corresponding targeted values. The linear regression function of the calibration is presented in fig. 2. The PG ratio was 3.4 below the critical value of $F_{9 ; 9 ; 0.99}=5.35$, indication that the selected working range is appropriate and the calibration curve can be used. The results obtained for the CRM analysis (tab. 2), showed that the recovery were $95 \%$ of the certified values.

The repeatability of the measurement, determined by a single operator on the same

Tab. 1. Confirmation of LoQ

\begin{tabular}{|c|c|c|c|c|c|}
\hline Replicate & $\begin{array}{l}\text { Concentration } \\
(\mathrm{mg} / \mathrm{kg})\end{array}$ & $\begin{array}{l}\text { Average } \\
\text { (mg/kg) }\end{array}$ & $\begin{array}{c}\mathrm{s} \\
(\mathrm{mg} / \mathrm{kg})\end{array}$ & $\begin{array}{l}\text { RSD } \\
(\%)\end{array}$ & $\begin{array}{c}\text { Recovery } \\
(\%)\end{array}$ \\
\hline 1 & 32 & \multirow{6}{*}{31.7} & \multirow{6}{*}{2.6} & \multirow{6}{*}{8.1} & \multirow{6}{*}{105} \\
\hline 2 & 30 & & & & \\
\hline 3 & 35 & & & & \\
\hline 4 & 28 & & & & \\
\hline 5 & 34 & & & & \\
\hline 6 & 31 & & & & \\
\hline
\end{tabular}

Tab. 2. Results of analysis of TPH Sandy Loam CRM

\begin{tabular}{ccc}
\hline $\begin{array}{c}\text { Found content } \\
(\mathrm{mg} / \mathrm{kg})\end{array}$ & $\begin{array}{c}\text { Certified content } \\
(\mathrm{mg} / \mathrm{kg})\end{array}$ & Recovery (\%) \\
\hline $3460 \pm 200$ & $3650 \pm 270$ & 95 \\
\hline
\end{tabular}




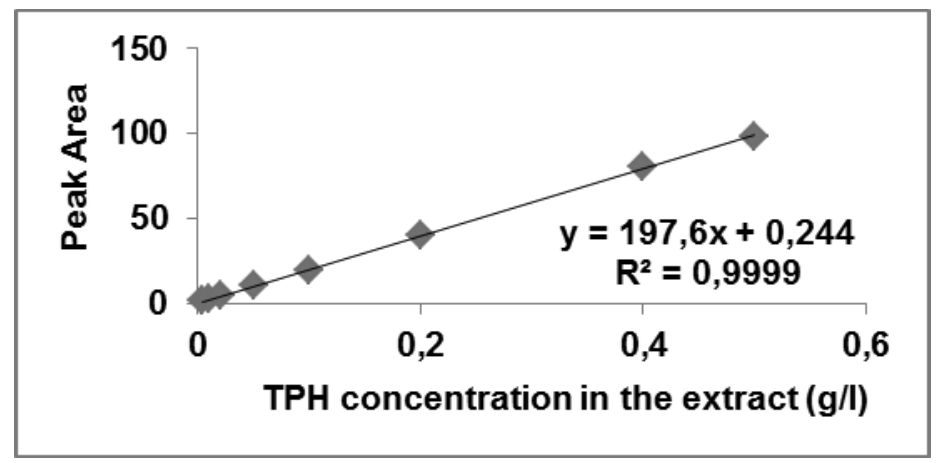

Fig. 2. The calibration curve for the determination of TPH in soil samples

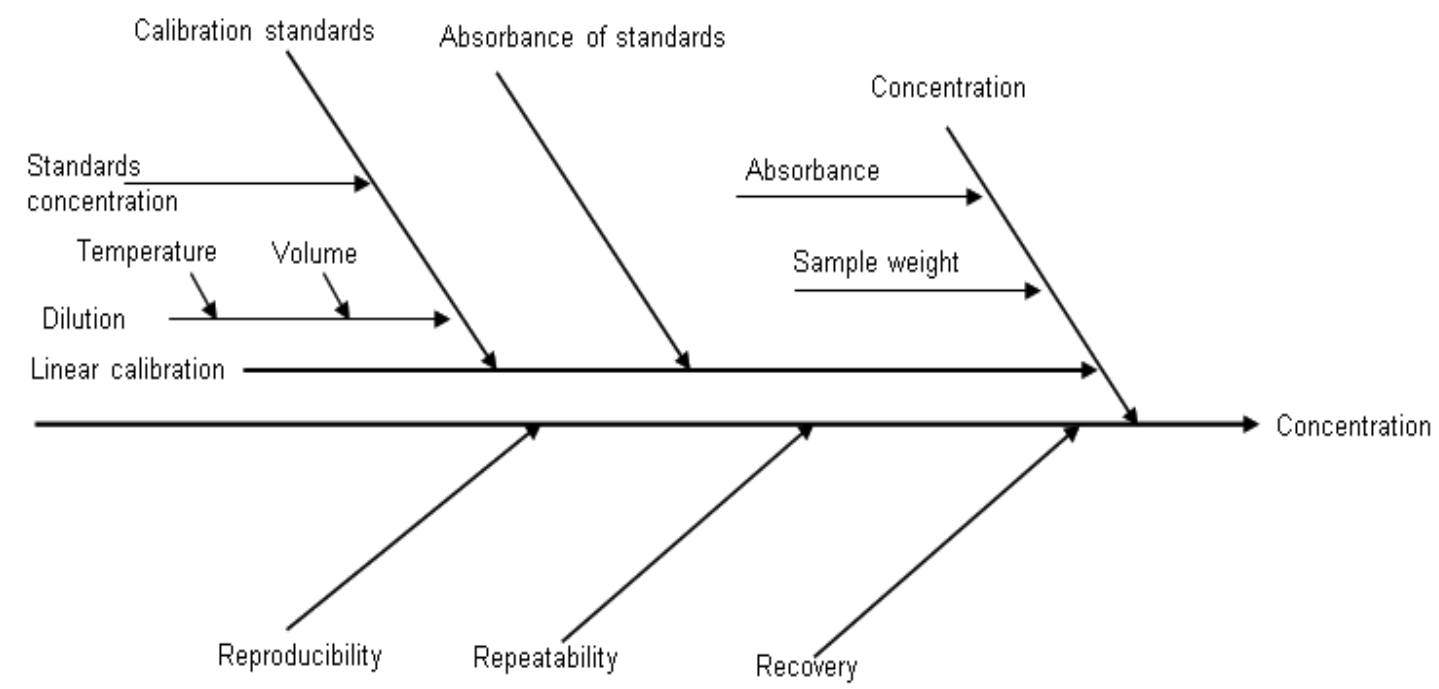

Fig. 3. Cause and effects diagram of uncertainties

Tab. 3. Uncertainty components of TPH determination in soil

\begin{tabular}{ccccccc}
\hline Source of uncertainty & Unit & Value & $\begin{array}{c}\text { Standard } \\
\text { uncertainty }\end{array}$ & Intervention & $\begin{array}{c}\text { Total standard } \\
\text { uncertainty }\end{array}$ & $\begin{array}{c}\text { Relative } \\
\text { uncertainty }\end{array}$ \\
\hline $\begin{array}{c}\text { Concentration of } \\
\text { standard }\end{array}$ & $\mathrm{g} / \mathrm{g}$ & 1,00003 & 0,00003 & 1 & 0,00003 & 0,00003 \\
\hline Weight of standard & $\mathrm{mg}$ & 500 & 0,05012 & 1 & 0,0501 & 0,00010 \\
\hline Volumetric flask & $\mathrm{ml}$ & 100 & 0,27 & 1 & 0,2700 & 0,00270 \\
\hline Volumetric flask & $\mathrm{ml}$ & 50 & 0,137 & 8 & 1,0960 & 0,02192 \\
\hline Pipette & $\mathrm{ml}$ & 2 & 0,0083 & 1 & 0,0083 & 0,00415 \\
\hline Pipette & $\mathrm{ml}$ & 5 & 0,0163 & 3 & 0,0489 & 0,00978 \\
\hline Pipette & $\mathrm{ml}$ & 10 & 0,0291 & 3 & 0,0873 & 0,00873 \\
\hline Pipette & $\mathrm{ml}$ & 20 & 0,0556 & 1 & 0,0556 & 0,00278 \\
\hline Pipette & $\mathrm{ml}$ & 25 & 0,0687 & 1 & 0,0687 & 0,00275 \\
\hline Sample weight & $\mathrm{g}$ & 10 & 0,00011 & 1 & 0,0001 & 0,00001 \\
\hline Equipment & $\mathrm{cm}-1$ & 2849 & 0,265 & 1 & 0,2650 & 0,00009 \\
\hline Calibration & $\mathrm{mg} / \mathrm{kg}$ & 0,160 & 0,001 & 1 & 0,00 & 0,00625 \\
\hline Reproducibility & $\mathrm{mg} / \mathrm{kg}$ & 2100 & 100,8 & 1 & 100,80 & 0,04800 \\
\hline
\end{tabular}


equipment, using six parallel samples, indicated an average concentration of $2100 \mathrm{mg} / \mathrm{kg}$ with the standard deviation of the repeatability of $4.8 \%$, below the targeted $20 \%$. The determination of the reproducibility by measurements in 10 different days by different operators resulted in an average TPH content of $2200 \mathrm{mg} / \mathrm{kg}$ with a $12.6 \%$ standard deviation of the reproducibility, below the targeted $20 \%$.

\section{Measurement uncertainty evaluation}

The identified main sources of measurement uncertainty were the uncertainty of delivered volumes, uncertainty of measured absorbance of the reference solutions, and recovery of the method. The contributions of repeatability to the measurement uncertainty were combined into one contribution for the overall experiment and were obtained from the method validation study performed in the laboratory. Recovery accounts for possible interferences in the method when soil samples with specific matrix are analysed. The sources of uncertainty and uncertainty components are schematically presented in the cause and effect diagram (fig. 3). The uncertainty components of THP determination from soil are presented in table 3 .

The combined relative uncertainty was found to be 0.055 , the combined measurement uncertainty was calculated to be $5.5 \%$. To calculate the expanded uncertainty of the result of a measurement at the $95 \%$ confidence level, the result for the combined uncertainty was multiplied by a coverage factor of 2 . Thus the expanded uncertainty of the TPH determination in soil by FT-IR method is $11 \%$.

A comparison between the calculated uncertainty and the observed variation based on control charts indicated that all the major sources of uncertainty were taken into consideration in the uncertainty budget.

\section{CONCLUSION}

In the present research work the FT-IR method for the determination of petroleum hydrocarbons in soils was validated. The method's figures of merit were studied, the main uncertainty components were identified and the measurement uncertainty budget was estimated. The FT-IR method allows the accurate determination of petroleum products from soil.

Acknowledgments. This work was supported by Romanian financing authority CNCS -UEFISCDI, Partnership program, project BIORESOL

\section{REFERENCES}

1. Drolc A, Pintar A (2012). Method validation and measurement uncertainty evaluation for measurement of mass concentration of organic acids in fermentation broths by using ion chromatography. Accred Qual Assur, 17: 323-330.

2. International Organization for Standardization (1995) Guide to the expression of uncertainty in measurement (GUM). JCGM 100:2008

3. Miclean M, Levei E, Gog A, Ferenczi L, Majdik C (2010). Determination of total petroleum hydrocarbons in contaminated soil by FT-IR and GC-FID methods. Studia UBB Chemia, 55(3): 83-91.

4. Okparanma RN (2013). Determination of total petroleum hydrocarbon (TPH) and polycyclic aromatic hydrocarbon (PAH) in soils: a review of spectroscopic and nonspectroscopic techniques. Appl Spectrosc Rev, 48 (6): 458-486.

5. Paiga P, Mendes L, Albergaria JT, Delerue-Matos CM (2012). Determination of total petroleum hydrocarbons in soil from different locations using infrared spectrophotometry and gas chromatography. Chem Pap 66 (8): 711-721.

6. S.L.R. Ellison, A. Williams (2012). Eurachem/CITAC guide: Quantifying Uncertainty in Analytical Measurement, Third edition, ISBN 978-0-948926-30-3.

7. Schwartz G, Ben-Dor E., Eshel G (2012). Quantitative analysis of total petroleum hydrocarbons in soils: comparison between reflectance spectroscopy and solvent extraction by 3 certified laboratories. Appl Environ Soil Sci, ID 751956, doi:10.1155/2012/751956. 